OPEN ACCESS

Edited by:

Elliot J. Roth,

Rehabilitation Institute of Chicago, USA

Reviewed by: Patrick Freund,

University of Zurich, Switzerland Ryan J. Felling,

Johns Hopkins School of Medicine, USA

*Correspondence: Johann Sellner j.sellner@salk.at

Specialty section: This article was submitted to Spinal Cord Medicine, a section of the journal Frontiers in Neurology

Received: 14 November 2016 Accepted: 29 March 2017 Published: 12 April 2017

Citation:

Pikija S, Mutzenbach JS, Kunz AB, Nardone R, Leis S, Deak I, McCoy MR, Trinka E and Sellner J (2017) Delayed Hospital Presentation and Neuroimaging in Non-surgical Spinal Cord Infarction. Front. Neurol. 8:143. doi: 10.3389/fneur.2017.00143

\section{Delayed Hospital Presentation and Neuroimaging in Non-surgical Spinal Cord Infarction}

\author{
Slaven Pikija', Johannes Sebastian Mutzenbach ${ }^{1}$, Alexander B. Kunz', Raffaele Nardone ${ }^{2,3}$, \\ Stefan Leis', Ildiko Deak', Mark R. McCoy ${ }^{4}$, Eugen Trinka ${ }^{1,3}$ and Johann Sellner ${ }^{1,5 *}$ \\ 'Department of Neurology, Christian Doppler Medical Center, Paracelsus Medical University, Salzburg, Austria, ${ }^{2}$ Department \\ of Neurology, Franz Tappeiner Hospital, Merano, Italy, ${ }^{3}$ Spinal Cord Injury and Tissue Regeneration Center, Paracelsus \\ Medical University, Salzburg, Austria, ${ }^{4}$ Division of Neuroradiology, Christian Doppler Medical Center, Paracelsus Medical \\ University, Salzburg, Austria, ${ }^{5}$ Department of Neurology, Klinikum rechts der Isar, Technische Universität München, \\ Munich, Germany
}

Background: Lack of timely recognition and neuroimaging may be a barrier to reperfusion efforts in acute spinal cord infarction.

Methods: We performed a retrospective study of patients diagnosed with acute non-surgical spinal cord infarction at our tertiary academic center from 2001 to 2015. We studied parameters associated with time from symptom onset to initial hospital presentation and magnetic resonance imaging (MRI) of the spinal cord.

Results: We identified 39 patients among whom anterior spinal artery syndrome was the most frequent presentation (87.2\%) and atherosclerosis the most common etiology (56.4\%). Nearly, half of the patients presented to the emergency department on the same day of symptom onset (48.7\%) but only nine (23.1\%) within the first $6 \mathrm{~h}$. Average time from symptom onset to spinal cord MRI was 3.2 days. We could not identify clinical, radiological, or outcome patterns associated with early vs. delayed presentation and imaging.

Discussion: Our study found a time lag from symptom onset to hospital presentation and spinal cord MRI in patients with acute spinal cord infarction. These findings point at low clinical suspicion of spinal cord syndromes and limited recognition as a potentially treatable medical emergency.

Keywords: spinal cord, stroke, ischemia, delay, reperfusion, thrombolysis, neuroimaging

\section{INTRODUCTION}

Acute spinal cord infarction is a rare disorder, which accounts for only $8 \%$ of all myelopathies and not more than $1 \%$ of all strokes (1). The condition is provoked by acute disruption of the spinal cord blood supply and results in neurological deficits linked to the supplied vascular territory (2). In the majority of reported patient series, $40-60 \%$ of patients had initial American Spinal Cord Injury Association (ASIA) Impairment Scale Grades A and B and a similar proportion remains wheelchair dependent on follow-up several years later $(3,4)$. Further, the most recent long-term follow-up studies reported a 5 -year mortality rate of $21-23 \%(5,6)$. 
Two major pathophysiological mechanisms of action can be distinguished for spinal cord infarction. Radicular artery territory infarcts are caused by occlusion of the anterior or posterior artery and central and transverse infarcts are the consequence of systemic hypoperfusion. The main causes of spinal cord infarction are aortic interventions and pathologies, which constitute around two-thirds of the cases (4). The non-surgical etiologies are dominated by atherosclerosis, followed by cardiac and arterioarterial embolism, global hypoxia, infection, hypercoagulable state, and vasculitis $(1,7)$. In $20-30 \%$ of the patients, the etiology remains unclear. The clinical spectrum of spinal cord infarction is broad and ranges from complete or incomplete spinal cord dysfunction with various degrees of sensorimotor and autonomic disturbances (8). In contrast to cerebral ischemic stroke, many patients with spinal cord infarcts suffer from pain, which is commonly located at the level of the spinal cord lesion. Further, symptoms often develop slower than in supratentorial ischemic stroke, sometimes taking up to several hours before reaching the plateau (9).

Stroke is a neurological emergency. The pressure for rapid stroke recognition and presentation to the emergency department (ED) is largely driven by the proven efficacy of systemic thrombolysis for cerebral ischemic stroke. Indeed, tissue plasminogen activator ( $t-P A)$ is an effective therapy for ischemic stroke involving both anterior and posterior circulations within the $4.5 \mathrm{~h}$ timeframe (10). More recently, a few case reports delivered insights to feasibility and both potential safety and efficacy of t-PA administration in acute spinal cord infarction (11-15). A timely diagnosis is a pre-requisite to allow administration of t-PA more frequently in patients with spinal cord infarction. For cerebral ischemic stroke, numerous studies examined barriers for the time from symptom onset to arrival at the ED, neuroimaging, administration of $\mathrm{t}-\mathrm{PA}$, and benefit for the treatment at a specialized stroke unit $(16,17)$.

Here, we characterized the spectrum of clinical manifestations and radiological presentations of non-surgical spinal cord infarction and studied potential determinants of pre- and in-hospital delays. Spinal cord infarction accounts only for a small group of ischemic strokes and is not widely known for the spectrum of clinical symptoms, potential treatability, and poor prognosis. Thus, we hypothesized that there are barriers for translating the established standards of care for acute cerebral ischemic stroke to spinal cord infarction.

\section{SUBJECTS AND METHODS}

\section{Patient Selection}

We performed a retrospective study of patients treated at a tertiary care center from January 2001 to July 2015.

Patients with spinal cord infarction were identified from the hospital database by using following search terms (in German): spinal cord ischemia, spinal cord infarction, ischemic myelopathy, and non-compressive myelopathy.

Thirty-nine patients fulfilled the diagnostic criteria that were

(a) acute or subacute (delay from onset to maximum clinical intensity up to $72 \mathrm{~h}$ ) spinal cord syndrome, (b) no plausible alternative explanation based on extensive clinical workup,

(c) radiological investigations with magnetic resonance imaging (MRI) of the spinal cord within 10 days from symptom onset.

The excluded patients had extrinsic spinal cord compression, spinal arterio-venous malformation, systemic and demyelinating disease, and paraneoplastic syndromes. One patient with posterior cord infarction was reported in a previous case study (18).

\section{Clinical and Paraclinical Workup}

Patients underwent standard diagnostic pathways for stroke, which included laboratory testing, evaluation of cardiovascular risk factors, and imaging. When in doubt of the diagnosis, a spinal tap was performed and analyzed for opening pressure, cell count, glucose, protein levels, lactate, hem-derived pigments, oligoclonal bands, immune electrophoresis, and the presence of blood-brain barrier dysfunction. The laboratory workup was amended with testing for autoimmune and paraneoplastic diseases, infections such as neurotropic viruses, HIV, Lyme borreliosis, and Treponema pallidum. Spinal MRI (Philips MR 1.5 T until 2007 and later Philips 3.0 T) was performed at least once in all patients. The patients were screened for aortic or vertebral artery pathology based on the level of the spinal cord syndrome. Standard transthoracic cardiac sonography was performed in all patients.

\section{Analysis of Demographics, Etiology, Clinical Features, and Outcome}

We studied demographics (age, sex), clinical symptoms at onset (acute pain in the neck, back, shoulder, chest, abdomen or head, or radicular pain), motor deficits at the ED (motor functions of the worst affected extremity, assessed by Medical Research Council scales), sensory level (the most caudal segment of the spinal cord with normal bilateral sensory functions), joint position sense and vibration testing, and urine retention. Further, we explored whether acute respiratory failure developed or not and mechanical ventilator support was required.

When determining the lesion level we used combined clinical and radiological findings. A follow-up scan was performed if the initial one was negative, or when the clinical course required reevaluation. We reviewed sagittal T1- and T2-weighted images, axial T2-weighted images at the suspected lesion level and diffusion-weighted imaging, if available. According to the clinical features and MRI findings, patients were classified as having anterior spinal artery (ASA), posterior spinal artery, central cord, or transverse cord infarction. We graded the extent of spinal cord injury with the ASIA Impairment Scale, as reported previously (19).

The etiology was based on the criteria and classification proposed by Nedeltchev et al. (9):

(i) atherosclerosis: history or features of vascular disease or presence of $>2$ vascular risk factors,

(ii) aortic pathologies: aortic aneurysms or dissections, 
(iii) degenerative spine disease at the level of the cord ischemia with the potential of radiculomedullary artery compression in patients without vascular risk factors,

(iv) cardiac embolism defined as the presence of previously or newly established atrial fibrillation without concurrent etiologies,

(v) systemic hypotension defined as an episode of mean arterial pressure below $50 \mathrm{~mm} \mathrm{Hg}$, and

(vi) idiopathic.

The analysis of vascular risk factors included following parameters:

- hypertension (systolic blood pressure $>140 \mathrm{~mm} \mathrm{Hg}$, diastolic blood pressure $>90 \mathrm{~mm} \mathrm{Hg}$ or both),

- diabetes mellitus (symptoms of diabetes plus fasting blood glucose $>126 \mathrm{mg} / \mathrm{dl}$ or current use of hypoglycemic agents),

- hyperlipidemia (cholesterol normal range $>200 \mathrm{mg} / \mathrm{dl}$, triglyceride normal range $>150 \mathrm{mg} / \mathrm{dl}$, or current use of lipid-lowering drugs),

- atrial fibrillation (ECG or transthoracic echocardiogram),

- previous cerebral infarctions or transient ischemic attacks (TIAs) (clinical history and chart records),

- myocardial infarction (clinical history, chart records, and ECG),

- heart diseases (congestive heart failure, arrhythmia, heart valve disease),

- renal disease,

- family histories of cerebrovascular attacks, and

- cigarette smoking.

Aortic disorders, particularly aortic dissection, aneurysm, or atheroma, were evaluated non-invasively by transthoracic echocardiogram, computed tomography, or MRI. Diagnostic or therapeutic angiograms were evaluated. We assessed outcome according to medical records at discharge. The categories were in-hospital death or death within 3 months, walk without help at discharge, with help of another person, wheelchair dependent, or bedridden.

\section{Statistical Analysis}

We used $\chi^{2}$ test, with Yates correction or Fisher's exact test, to compare qualitative variables and the non-parametric Kruskal-Wallis test to compare quantitative variables. We performed statistics by using STATA SE 13.0 for Windows (StataCorp LP, TX, USA).

\section{RESULTS}

\section{Demographics}

The search for non-surgical cases of spinal cord infarction revealed 39 patients, 20 were men (51.3\%). Most patients were admitted within the last few years. While five patients were identified in the period from 2001 to 2005, this number increased to 11 from 2006 to 2010 and eventually 23 cases within the last 4 years.

Median age was 69 years (range 44-90). Vascular risk factors were dominated by arterial hypertension $(64.1 \%)$, the runner-up was diabetes $(30.8 \%)$. One-fifth had a history of cerebral TIA or stroke. Atherosclerosis was the presumed etiology in $56.4 \%$ of cases. Further demographics, cardiovascular risk factors, distribution of etiologies, and comorbidities are outlined in Table 1 .

\section{Clinical Findings and Presentation at the ED}

Bilateral and unilateral anterior spinal artery syndromes were the most frequent clinical presentations (71.8 and $15.4 \%$, respectively). ASIA B impairment was most frequent in bilateral anterior spinal artery syndromes (38.5\%), a specific time course of clinical disturbances could not be identified when compared to the other syndromes.

A sensory level was found most commonly within thoracic dermatomes (46.1\%). Pain history was unclear in 4 (10\%) and not reported in 14. Pain preceded other symptoms in $17 / 21$ (73.9\%) and developed in conjunction with other symptoms in the remaining 4. Pain persisted until transfer to rehabilitation in the majority. The localization of pain was usually in line with the spinal cord lesion on MRI. However, there was a discrepancy for pain and lesion level in six patients. Autonomic dysfunction was rare and reported only in two cases (5.4\%) in terms of urinary incontinence. A detailed presentation of clinical findings is shown in Table 2.

One extreme outlier with ASIA Impairment Scale B was excluded for the analysis of time to hospital admission. The average time from symptom onset to ED presentation in 38 patients was 2.2 days (SD 4.1). There was no significant difference for patients with different ASIA Impairment Scales, as shown in Table 2.

We further examined the courses of 13 patients $(33.3 \%)$, in whom the exact time (in minutes) from symptom onset to ED presentation was documented. Of them, four arrived at the ED later than $6 \mathrm{~h}$ after symptom onset. The affected spinal arterial territory (anterior or posterior), presumed etiology, presence of pain, and ASIA scores on admission were not associated with time from symptom onset to ED presentation (Table 5).

Only nine patients were seen in the ED within the "window of opportunity" of less than $6 \mathrm{~h}(23 \%)$. None of the patients

TABLE 1 | Demographics of 39 patients with non-surgical spinal cord infarction.

\begin{tabular}{lr}
\hline Parameter & \\
\hline Mean (SD) age (years) & $67.8(12.4)$ \\
Women, N (\%) & $19(48.7)$ \\
Vascular risk factors, N (\%) & \\
$\quad$ Hypertension & $25(64.1)$ \\
Diabetes mellitus & $12(30.8)$ \\
Angina pectoris/peripheral arterial occlusive disease & $6(15.4)$ \\
History of stroke/transient ischemic attack & $8(20.5)$ \\
Hyperlipidemia & $10(25.6)$ \\
Possible etiology, $N$ (\%) & \\
Atherosclerosis & $22(56.4)$ \\
Aortic pathology & $4(10.3)$ \\
Degenerative spinal disease & $4(10.3)$ \\
Cardiac embolism & $2(5.1)$ \\
Systemic hypotension & $2(5.1)$ \\
latrogenic & $2(5.1)$ \\
Unknown & $3(7.7)$
\end{tabular}


TABLE 2 | Clinical syndromes and time to emergency department (ED) presentation and spinal cord magnetic resonance imaging (MRI) of 39 patients with non-surgical spinal cord infarction.

\begin{tabular}{|c|c|c|c|c|c|}
\hline \multirow[b]{2}{*}{ Parameter } & \multicolumn{4}{|c|}{$\begin{array}{l}\text { American Spinal Cord Injury Association } \\
\text { Impairment Scale, } N(\%)\end{array}$} & \multirow[b]{2}{*}{ Total } \\
\hline & A & B & C & D & \\
\hline $\begin{array}{l}\text { Degree of impairment } \\
\text { at presentation, } N(\%)\end{array}$ & $2(5.1)$ & $10(25.6)$ & $19(48.7)$ & $8(20.5)$ & 39 (100) \\
\hline \multicolumn{6}{|c|}{ Neurological syndrome, N (\%) } \\
\hline Anterior spinal artery & $2(5.1)$ & $5(12.8)$ & $15(38.5)$ & $6(15.4)$ & $28(71.8)$ \\
\hline Anterior unilateral & 0 & $2(5.1)$ & $2(5.1)$ & $2(5.1)$ & $6(15.4)$ \\
\hline Posterior unilateral & 0 & $1(2.6)$ & $1(2.6)$ & 0 & $2(5.1)$ \\
\hline Central & 0 & $1(2.5)$ & 0 & 0 & $1(2.6)$ \\
\hline Posterior syndrome & 0 & $1(2.6)$ & 0 & 0 & $1(2.6)$ \\
\hline $\begin{array}{l}\text { Complete spinal } \\
\text { cord syndrome }\end{array}$ & 0 & 0 & $1(2.6)$ & 0 & $1(2.6)$ \\
\hline \multicolumn{6}{|l|}{ Neurological level, N (\%) } \\
\hline Cervical & 0 & $3(7.7)$ & $3(7.7)$ & $1(2.6)$ & $7(17.9)$ \\
\hline Thoracic & $1(2.6)$ & $5(12.8)$ & $10(25.6)$ & $2(5.1)$ & $18(46.1)$ \\
\hline Lumbosacral & 0 & 0 & $1(2.6)$ & 0 & $1(2.6)$ \\
\hline Overlapping & $1(2.6)$ & $2(5.1)$ & $5(12.8)$ & $5(12.8)$ & 13 (33.3) \\
\hline Pain reported, $N(\%)$ & $1(2.6)$ & $6(15.4)$ & $11(28.2)$ & $4(10.3)$ & $22(56.4)$ \\
\hline $\begin{array}{l}\text { Autonomic } \\
\text { disturbance, } N(\%)\end{array}$ & 0 & 0 & $2(5.4)$ & 0 & $2(5.4)$ \\
\hline $\begin{array}{l}\text { Mean (SD) days to ED } \\
\text { presentation }\end{array}$ & $1.5(2.1)^{\mathrm{a}}$ & $0.6(0.5)^{\mathrm{a}}$ & $2.7(4.5)$ & $3.1(5.4)$ & $2.2(4.1)^{\mathrm{a}}$ \\
\hline $\begin{array}{l}\text { Mean (SD) days from } \\
\text { symptom onset to } \\
\text { first MRI }\end{array}$ & $1.5(2.1)$ & $5.7(14.2)$ & $1.7(2.0)$ & $4.6(10.1)$ & $3.2(8.1)$ \\
\hline $\begin{array}{l}\text { Mean (SD) days from } \\
\text { symptom onset to } \\
\text { second MRI }\end{array}$ & - & $7.0(3.6)$ & $10.2(11.7)$ & $6.5(3.5)$ & $8.6(8.9)$ \\
\hline
\end{tabular}

${ }^{a}$ Calculation excluding one outlier.

received t-PA. In this acute period, MRT was conclusive in only one patient (number 37 in Table 3). This patient had acute onset of pain in both shoulders accompanied with tetraparesis. MRI showed a T2-lesion from C2 to Th2 consistent with central spinal cord infarction. The sensory symptoms were mild and spinal tap revealed high protein values $(85 \mathrm{mg} / \mathrm{dl})$.

\section{Spinal Cord MRI}

All patients were examined with MRI of the spine; exact times were documented in 18 patients. Median time from admission to first MRI 4:59 h (inter-quartile range 2:10-11:20 h).

The entire spine was studied in $75 \%$ of the patients, and exclusive examination of the cervical and thoracolumbar cord was performed in 18 and 7\%, respectively. Further details are outlined in Tables 2 and 4. MRI lesions were not detected in four patients (10\%) even with repeated spinal cord MRI, these were patients $13,14,19$, and 38. Spinal CT was performed in 17/39 (22.0\%) and 10 patients underwent conventional spinal angiography (25.6\%). One patient had an occlusion of the Adamkiewicz artery (arteria radicularis magna).

The first T2-weighted spinal cord MRI was diagnostic in $4 / 39(10.3 \%)$ of patients, the gain was slightly higher with DWI $(5 / 39,12.8 \%)$. A second MRI of the spinal cord was performed in 29 patients $(74.4 \%)$, and revealed a T2- and DWI lesion in
$10 / 29(34.4 \%)$ and 4/29 (13.8\%), respectively. A third MRI was performed in eight $(20.5 \%)$. Mean time from symptom onset to MRI was 3.2 days (SD 8.1). A trend for an earlier spinal cord MRI was found for patients with pain (1.2 vs. 5.8 days, $p=0.087$ ).

\section{Laboratory Findings}

Workup for vasculitis and autoimmune disorders was performed in $21(53.4 \%)$ patients and was negative in all of them. A spinal tap was performed in 10/39 (25.6\%). Elevated protein concentration was found in eight $(80 \%)$ and a pleocytosis was present in one. Fourteen patients were examined with somatosensory evoked potentials (35.9\%) and 9/14 (64.2\%) had central conduction deficits.

\section{Outcomes}

Four patients died, details of these patients are shown in Table 3. One patient died on day 6 , the remaining more than 3 months after admission. One patient was able to walk without help $(2.6 \%)$ at discharge, 2 with help of another person (12.8\%), 15 (38.5\%) were discharged in a wheelchair, and 5 (12.8\%) were bedridden. For 13 patients $(33.3 \%)$, the exact discharge status was unknown. ASIA score at symptom onset was not associated with the clinical status at discharge.

\section{DISCUSSION}

This study characterized the clinical and radiological spectrum of non-surgical spinal cord infarction and analyzed potential barriers to diagnosis and treatment. The retrospective chart review identified 39 patients from a tertiary care center over a period of 14 years with a diagnostic peak within the last 4 years. Nearly half of the patients presented on the same day of symptom onset (48.7\%) but only nine (23\%) within the first 6 h. Further substantial time lags were identified for spinal cord MRI with average time to a first spinal MRI of 3.2 days. Discrimination of vascular and inflammatory diseases turned out to be challenging in some cases, and also required CSF testing and repeated MRI in a few cases. These findings point at low clinical suspicion of spinal cord syndromes and recognition as a potentially treatable medical emergency. Notably, we could not identify demographic, clinical, or radiological features associated with delays in ED presentation and spinal MRI.

Most infarcts present as an anterior cord syndrome, which results from vascular occlusion or hypoperfusion of the ASA territory and its watershed area (20). In our cohort, the bilateral ASA territory was most frequently affected (72\%). Previous studies of non-surgical spinal cord infarction with a similar patient number reported a frequency of $51-75 \%$ for anterior cord syndrome $(8,21,22)$. Lesion localization in our study was thoracic cord in $46 \%$ of patients and the distribution varies largely in the literature $(39-75 \%)(9,22)$. The common affection of the thoracic cord might be related to insufficient collaterals in this region and thus the thoracic cord spine being sensitive to systemic hypotension (4). The clinical outcome was unfavorable in about $50 \%$. It needs to be acknowledged that our study is skewed toward an elderly population (67.8 years). Further, we only studied short-term 
TABLE 3 | Clinical presentation and short-term outcome of 39 patients with non-surgical spinal cord infarction.

\begin{tabular}{|c|c|c|c|c|c|c|c|c|}
\hline No. & Age & Gender & Possible causes & Location of pain & $\begin{array}{c}\text { Sensory } \\
\text { level }\end{array}$ & $\begin{array}{c}\text { American Spinal Cord Injury } \\
\text { Association Impairment Scale } \\
\text { Grade }\end{array}$ & $\begin{array}{l}\text { Mobility at } \\
\text { discharge }\end{array}$ & $\begin{array}{c}\text { In-hospital } \\
\text { death }\end{array}$ \\
\hline 1 & 87 & $M$ & Atherosclerosis & Whole body & Th12 & $\mathrm{B}$ & Not mobile & \\
\hline 2 & 58 & $M$ & Degenerative spinal disease & Head and neck & C3-Th4 & $\mathrm{D}$ & - & \\
\hline 3 & 76 & M & Atherosclerosis & & Th11 & $\mathrm{C}$ & Not mobile & \\
\hline 4 & 84 & $\mathrm{~F}$ & Atherosclerosis & & C3-C7 & $\mathrm{C}$ & Not mobile & \\
\hline 5 & 68 & $\mathrm{~F}$ & Atherosclerosis & Buttocks both sides & Th12 & $\mathrm{D}$ & With help & \\
\hline 6 & 63 & M & Atherosclerosis & & Th8 & $\mathrm{D}$ & - & \\
\hline 7 & 70 & M & Atherosclerosis & Upper abdomen & $\mathrm{C} 3$ & $\mathrm{C}$ & & Yes \\
\hline 8 & 72 & $\mathrm{~F}$ & latrogen & & Th9 & $\mathrm{B}$ & - & \\
\hline 9 & 84 & M & Cardiac embolism & & Th7 & $\mathrm{B}$ & & Yes \\
\hline 10 & 54 & $\mathrm{~F}$ & Degenerative spinal disease & Neck with shoulders & C6 & $\mathrm{B}$ & Wheelchair & \\
\hline 11 & 75 & M & Aortic pathology & Chest and back & Th1 & $\mathrm{C}$ & Wheelchair & \\
\hline 12 & 52 & M & Aortic pathology & & Th4 & $\mathrm{C}$ & With help & \\
\hline 13 & 45 & $\mathrm{~F}$ & Unknown & Chest spine & $\mathrm{C} 2$ & $\mathrm{C}$ & - & \\
\hline 14 & 62 & M & Degenerative spinal disease & Both scapulas to arms & C5 & $\mathrm{D}$ & With help & \\
\hline 15 & 52 & $\mathrm{~F}$ & Atherosclerosis & Left abdominal & Th5 & $A$ & - & \\
\hline 16 & 69 & $\mathrm{~F}$ & Atherosclerosis & Lumbar & Th12 & $\mathrm{C}$ & - & \\
\hline 17 & 58 & M & Atherosclerosis & Lumbar spine & Th9 & B & - & \\
\hline 18 & 75 & $\mathrm{~F}$ & Aortic pathology & & Th11 & $\mathrm{D}$ & Wheelchair & \\
\hline 19 & 68 & M & Atherosclerosis & Left quadriceps & Th9 & $\mathrm{D}$ & Wheelchair & \\
\hline 20 & 70 & $\mathrm{~F}$ & Atherosclerosis & & Th12 & $A$ & Not mobile & \\
\hline 21 & 82 & $\mathrm{~F}$ & Systemic hypotension & & Th6 & C & Wheelchair & \\
\hline 22 & 77 & M & Atherosclerosis & Inguinal & Th7 & $\mathrm{C}$ & With help & \\
\hline 23 & 61 & M & Atherosclerosis & Between scapula & C4 & $D$ & - & \\
\hline 24 & 85 & $\mathrm{~F}$ & Systemic hypotension & & Th12 & $\mathrm{B}$ & & Yes \\
\hline 25 & 64 & $\mathrm{~F}$ & Degenerative spinal disease & Lumbar spine & Th12 & $\mathrm{C}$ & Wheelchair & \\
\hline 26 & 57 & M & Atherosclerosis & & Th9 & $\mathrm{C}$ & Wheelchair & \\
\hline 27 & 90 & $\mathrm{~F}$ & Atherosclerosis & & Th12 & $\mathrm{C}$ & - & \\
\hline 28 & 64 & $\mathrm{~F}$ & Atherosclerosis & Both legs & L1 & B & - & \\
\hline 29 & 70 & $M$ & Unknown & Lumbar spine & Th4 & $\mathrm{C}$ & - & \\
\hline 30 & 70 & M & Cardiac embolism & & Th10 & B & Not mobile & \\
\hline 31 & 45 & $\mathrm{~F}$ & Idiopathic & Both arms & C5 & $\mathrm{C}$ & Wheelchair & \\
\hline 32 & 61 & $\mathrm{~F}$ & Atherosclerosis & Neck both shoulders & C3 & $\mathrm{B}$ & Wheelchair & \\
\hline 33 & 79 & $M$ & Atherosclerosis & & Th9 & $\mathrm{C}$ & - & \\
\hline 34 & 70 & $M$ & Atherosclerosis & Neck both shoulders & $\mathrm{C} 2$ & $\mathrm{C}$ & Wheelchair & \\
\hline 35 & 84 & $\mathrm{~F}$ & Atherosclerosis & & $\mathrm{C} 4$ & $\mathrm{D}$ & Wheelchair & \\
\hline 36 & 57 & $\mathrm{~F}$ & Atherosclerosis & & Th12 & $\mathrm{C}$ & Wheelchair & \\
\hline 37 & 84 & $\mathrm{~F}$ & Aortic pathology & & C5 & $\mathrm{B}$ & Alone & $Y_{e s}^{a}$ \\
\hline 38 & 59 & $\mathrm{~F}$ & Atherosclerosis & Left leg & Th6 & C & - & \\
\hline 39 & 45 & $M$ & latrogenic & & Th6 & $\mathrm{C}$ & Wheelchair & \\
\hline
\end{tabular}

aThe patient died in hospital after transfer to internal medicine due to heart failure.

F, female; M, male; C, cervical; Th, thoracal; -, unknown.

outcome and gradual improvement over up to a year can be observed $(4,5,23)$.

Cerebral stroke is characterized by a sudden onset of clinical deficits. This contrasts the situation in spinal cord infarction, where symptoms are often preceded or accompanied by acute pain and develop over a longer period of time $(21,24)$. Indeed, in non-surgical spinal cord infarction the plateau of sensory, motor, and autonomic dysfunction ranges from minutes to more frequently several hours $(8,20)$. Patients with cerebral infarcts in comparable cohorts tended to be older have more cardiovascular risk factors and more frequently experience a TIA (24-26). Further, while a history of stroke or TIA is frequent in cerebral stroke, we corroborate previous studies that spinal cord TIAs are rare $(8,9,22)$. In our series, vascular risk factors were present in a high proportion of patients and atherosclerosis was the most common etiology. Nowadays, patients, caregivers, and health care professionals are aware of clinical symptoms related to cerebral stroke and recognize time as a key issue for treatment. This awareness can be taken as a result of media campaigns and structural adaptations within healthcare systems by defining stroke-like presentations as a medical emergency $(27,28)$. Our findings of a delayed presentation at the ED suggest that the clinical spectrum of non-surgical spinal cord infarction is less known in the public and potentially among primary care physicians. In our cohort, neither extent of motor disturbances, pain, nor other factors was associated with earlier hospital arrival. Occurrence of pain was frequent prior to the development of neurological deficits. The clinical presentation, however, might be misjudged as radicular nerve compression, cardiac emergency, or aortic pathology. The reported delays are unfortunate, as spinal cord infarction is associated with detrimental functional outcome (29). Further, timely admission to the stroke unit might be associated with 
TABLE 4 | Spinal cord MRI findings of 39 patients with non-surgical spinal cord infarction.

\begin{tabular}{|c|c|c|c|c|c|c|}
\hline No. & $\begin{array}{c}\text { Time from symptom onset } \\
\text { to MRI (in days) }\end{array}$ & MRI level & $\begin{array}{l}\text { DWI positive on first } \\
\text { MRI }\end{array}$ & $\begin{array}{l}\text { T2 signal positive on } \\
\text { first MRI }\end{array}$ & $\begin{array}{l}\text { DWI positive on } \\
\text { second MRI }\end{array}$ & Spinal angiography \\
\hline 1 & 5 & $\mathrm{~N} / \mathrm{A}$ & No & - & & \\
\hline 2 & 0 & C3-Th4 & No & - & & \\
\hline 3 & 0 & N/A & No & - & No & \\
\hline 4 & 41 & C3-C7 & Yes & + & & \\
\hline 5 & 0 & Th12-L1 & No & - & Yes & Negative \\
\hline 6 & 5 & N/A & No & - & No & \\
\hline 7 & 4 & C3-C7; Th1-Th11 & No & - & No & \\
\hline 8 & 1 & Th9-conus & & - & & \\
\hline 9 & 2 & Th7 & No & + & & \\
\hline 10 & 1 & C6 & & - & & \\
\hline 11 & 0 & Th1/Th4 & No & - & & \\
\hline 12 & 6 & Th4-Th6 & Yes & - & & \\
\hline 13 & 0 & C2-Th2 & No & - & Yes & Negative \\
\hline 14 & 2 & C5-Th2 & No & + & & \\
\hline 15 & 0 & Th5-Th8 & Yes & - & & Negative \\
\hline 16 & 7 & Th12/conus & No & - & Yes & \\
\hline 17 & N/A & N/A & & + & & \\
\hline 18 & 3 & N/A & & - & & \\
\hline 19 & 0 & Th9/Th12 & No & - & & \\
\hline 20 & 0 & Th12-L1 & No & - & & \\
\hline 21 & & Th6 & & - & & \\
\hline 22 & 0 & Th7-conus & No & - & & \\
\hline 23 & 0 & N/A & & + & & Negative \\
\hline 24 & 1 & Th12 & No & - & & \\
\hline 25 & 0 & Th12-L1 & & - & & \\
\hline 26 & 0 & Th9/Th10 & No & + & & \\
\hline 27 & 1 & Thoracic & No & - & & \\
\hline 28 & 0 & $\mathrm{~N} / \mathrm{A}$ & & - & & $\begin{array}{c}\text { Arteria radicularis magna } \\
\text { occlusion }\end{array}$ \\
\hline 29 & $\mathrm{~N} / \mathrm{A}$ & $\mathrm{N} / \mathrm{A}$ & No & + & & Negative \\
\hline 30 & 29 & Th10/Th11 & & - & & \\
\hline 31 & 0 & C5/C6 & No & - & & Negative \\
\hline 32 & 1 & C3/C4 & Yes & + & & Negative \\
\hline 33 & 1 & Th9-L1 & No & - & & \\
\hline 34 & 3 & $\mathrm{C} 2 / \mathrm{C} 4$ & & - & & \\
\hline 35 & 1 & C4-C7 & No & + & & \\
\hline 36 & 0 & Th12 & No & - & & Negative \\
\hline 37 & 0 & C5, C6 & Yes & - & & \\
\hline 38 & 1 & Th6/7 & No & - & & Negative \\
\hline 39 & 1 & Th6-conus & No & + & Yes & \\
\hline
\end{tabular}

N/A, not available; C, cervical; Th, thoracal.

better outcome and thrombolytic therapies appear to have a logical role in the management of spinal cord infarction $(6,29)$. Stroke unit care has been shown to be beneficial regardless of the stroke etiology following acute ischemic and hemorrhagic stroke (30). Beyond the established stroke unit standards of care, initiation of antiplatelet therapy or heparin would be the obvious consequence with the presence of vascular risk factors or potentially progressive etiologies of spinal cord infarction such as vertebral artery dissection (29). In traumatic spinal cord injury, higher blood pressure correlated with better neurological recovery (31). This observation backs the recommendation to raise the mean arterial pressure above $85-95 \mathrm{~mm} \mathrm{Hg}$ for the initial 5-7 days in traumatic spinal cord injury. In the lack of study evidence and obvious pathophysiological benefits of improved spinal cord perfusion, this concept could be translated to spinal cord infarction $(19,20)$. Further, a lumbar drain that allows lowering of CSF pressure to $10-15 \mathrm{~mm} \mathrm{Hg}$ to improve spinal cord perfusion in spinal cord ischemia may be considered $(20,32)$ The guidelines of the German Neurological Society have listed a lumbar drain for thoracic anterior spinal artery syndromes which occur during aortic or thoracic surgery. By contrast, the German expert panel concluded that there is not sufficient evidence to recommend thrombolysis or endovascular treatment options. Whether antiplatelet therapy leads to hemorrhagic complications in this context is unclear. Freedman and coworkers also suggest the usage of high-dose steroids in non-traumatic spinal cord infarction according to the traumatic spinal cord injury protocol within the first $3 \mathrm{~h}$ due to limited side-effects and lack of proven other treatment options (20). Anticonvulsants administered at therapeutic doses for the management of neuropathic pain were shown to enhance motor recovery after acute spinal cord injury (33). Notably, early administration (i.e., within 1 month) for gabapentinoids, such as pregabalin and gabapentin, was integral for enhanced recovery. 
TABLE 5 | Time from symptom onset to presentation in 13 patients with non-surgical spinal cord infarction.

\begin{tabular}{|c|c|c|c|c|}
\hline & $\begin{array}{l}\text { Within } 6 \text { h } \\
(N=9)\end{array}$ & $\begin{array}{c}\text { After } 6 \mathrm{~h} \\
(N=4)\end{array}$ & $\chi^{2}$ & $\begin{array}{c}p \\
\text { Value }\end{array}$ \\
\hline Anterior spinal artery territory $(N=9)$ & 77.9 & 50.0 & 1.000 & 0.317 \\
\hline Other arterial territories $(N=4)$ & 22.2 & 50.0 & & \\
\hline Atherosclerotic etiology $(N=7)$ & 55.6 & 50.0 & 0.034 & 0.853 \\
\hline $\begin{array}{l}\text { Other etiologies of spinal cord } \\
\text { infarction }(N=6)\end{array}$ & 44.4 & 50.0 & & \\
\hline Pain $(N=7)$ & 44.4 & 75.0 & 1.040 & 0.308 \\
\hline No pain $(N=6)$ & 55.6 & 25.0 & & \\
\hline $\begin{array}{l}\text { American Spinal Cord Injury } \\
\text { Association (ASIA) Impairment Scale } \\
\text { Grades A-C }(N=11)\end{array}$ & 88.9 & 75.0 & 0.410 & 0.522 \\
\hline $\begin{array}{l}\text { ASIA Impairment Scale Grade D } \\
(N=2)\end{array}$ & 11.1 & 25.0 & & \\
\hline
\end{tabular}

Percentages are shown for patients within and beyond $6 \mathrm{~h}$ from symptom onset.

We found substantial time barriers to the realization of thrombolysis and admission to the stroke unit. On the one hand, there are difficulties of clinical recognition and unusual disease evolution due to the slow development of the plateau in contrast to cerebral infarction. On the other hand, it is unclear which examinations in addition to the workup for cerebral stroke are required to rule out potential contraindications. Obviously, an MRI of the entire spine with T2, DWI, and post-contrast T1 is required to evaluate other causes of myelopathy including intramedullary and extraand intradural pathologies (25). However, the detection of a myelopathy on MRI is not specific for spinal cord infarction. Further, it is a key to rule out life-threatening contraindications of t-PA therapy and causes of spinal cord infarction including aortic dissection. The exclusion of metabolic, cardiac, and cerebral pathologies requires additional diagnostic means such as CT scan of the brain, electrocardiogram, and laboratory testing. When resources are available, some authors also suggest spinal CT arteriography to visualize vessel occlusions and proceed with direct intra-arterial thrombolysis $(12,20)$. We identified significant delays from symptom onset to spinal cord imaging as another major obstacle to initiate systemic thrombolysis. Yet, whether a time window of $4.5 \mathrm{~h}$ or even beyond this period can be translated to spinal cord infarction remains unclear $(34,35)$. The few case reports available seem to confirm the safety profile within the $4.5 \mathrm{~h}$ time frame (11-14). Another issue is the fact that a T2/DWI mismatch concept is not established for spinal cord infarction and dynamics of lesion evolution are only scarcely known. T2-weighted imaging in spinal cord infarction may not visualize a lesion within the first $12-15 \mathrm{~h}$ (25). Treatment with $\mathrm{t}$-PA in cerebral stroke is based on exclusion of contraindications and is established in the lack of a detectable brain lesion in the acute phase. This line of thought has yet to be extended to spinal cord infarction. Typical for bilateral anterior spinal cord infarction are hyperintense lesions on axial T2-imaging in the region of the anterior horns illustrating the "snake eye" or "owl's eye" configuration. Lesions and pathologies on MRI, however, are not uniform and include a pencil-like lesion pattern on T2, various degrees of cord swelling, and enhancement on post-contrast
T1 (25). Superiority of early lesion detection by DWI has been reported not only in cerebral stroke but also in spinal cord infarction $(25,36,37)$. In our series, a lesion regardless of DWI or T2 was present on initial imaging in $15.4 \%$ and we corroborated a slightly higher yield with DWI. The exact time course of lesion development remains to be elucidated. Treatment decision for t-PA or should be guided by clinical presence of a spinal cord syndrome, exclusion of contraindication, and adherence to the time window proposed for cerebral stroke.

The retrospective nature of the study, the number of patients with exact time of symptom onset, and scarce documentation of clinical evolution are limitations of the study. Further, this study reports a single and tertiary care center experience and awaits confirmation from other settings and countries.

\section{CONCLUSION}

We confirm the notion that early hospital presentation and timely neuroimaging of patients with spinal cord infarction is rare. With regard to opening the time window for thrombolysis and stroke unit care for more patients with spinal cord infarction, we could not identify demographic, clinical, or radiological characteristics, which determine time delays for the diagnosis of spinal cord infarction. There is an urgent need to raise the awareness of this rare syndrome in order to augment the rate of treatment interventions directed at reperfusion. Even if thrombolysis cannot be performed due to contraindications or ED presentation beyond the time frame, stroke unit care might positively affect outcome as for cerebral stroke. Double-blinded randomized studies for spinal cord infarction cannot be expected within the next years. Prospective databases of patients treated with t-PA according to a uniform protocol, which adheres to the established standards, might shed further light to the efficacy and safety of this rare but still devastating cause of permanent neurological disability.

\section{ETHICS STATEMENT}

Retrospective and non-interventional studies do not require an ethical approval according to national law. The Medical Ethics Committee of the County of Salzburg reviewed the protocol and waived the requirement for additional approval (415-EP/73/539-2015).

\section{AUTHOR CONTRIBUTIONS}

JS and SP: concept, data acquisition, data analysis, drafting, and revising. JM: data acquisition and revising. AK, RN, and SL: data analysis and revising. ID and MM: data acquisition and data analysis. ET: data analysis, and revising.

\section{FUNDING}

The article processing charge was covered by the Spinal Cord Injury and Tissue Regeneration Center, Paracelsus Medical University, Salzburg, Austria. 


\section{REFERENCES}

1. Rubin MN, Rabinstein AA. Vascular diseases of the spinal cord. Neurol Clin (2013) 31(1):153-81. doi:10.1016/j.ncl.2012.09.004

2. Minagar A, Rabinstein AA. The human spinal cord. Neurol Clin (2013) 31(1):xiii-xiv. doi:10.1016/j.ncl.2012.09.015

3. Rigney L, Cappelen-Smith C, Sebire D, Beran RG, Cordato D. Nontraumatic spinal cord ischaemic syndrome. JClin Neurosci (2015) 22(10):1544-9. doi:10.1016/j.jocn.2015.03.037

4. Robertson CE, Brown RD Jr, Wijdicks EF, Rabinstein AA. Recovery after spinal cord infarcts: long-term outcome in 115 patients. Neurology (2012) 78(2):114-21. doi:10.1212/WNL.0b013e31823efc93

5. New PW, McFarlane CL. Survival following spinal cord infarction. Spinal Cord (2013) 51(6):453-6. doi:10.1038/sc.2013.14

6. Hanson SR, Romi F, Rekand T, Naess H. Long-term outcome after spinal cord infarctions. Acta Neurol Scand (2015) 131(4):253-7. doi:10.1111/ ane. 12343

7. Heldner MR, Arnold M, Nedeltchev K, Gralla J, Beck J, Fischer U. Vascular diseases of the spinal cord: a review. Curr Treat Options Neurol (2012) 14(6):509-20. doi:10.1007/s11940-012-0190-9

8. Novy J, Carruzzo A, Maeder P, Bogousslavsky J. Spinal cord ischemia: clinical and imaging patterns, pathogenesis, and outcomes in 27 patients. Arch Neurol (2006) 63(8):1113-20. doi:10.1001/archneur.63.8.1113

9. Nedeltchev K, Loher TJ, Stepper F, Arnold M, Schroth G, Mattle HP, et al. Long-term outcome of acute spinal cord ischemia syndrome. Stroke (2004) 35(2):560-5. doi:10.1161/01.STR.0000111598.78198.EC

10. Prabhakaran S, Ruff I, Bernstein RA. Acute stroke intervention: a systematic review. JAMA (2015) 313(14):1451-62. doi:10.1001/jama.2015.3058

11. Etgen T, Hocherl C. Repeated early thrombolysis in cervical spinal cord ischemia. J Thromb Thrombolysis (2016) 42(1):142-5. doi:10.1007/ s11239-015-1332-1

12. Lee K, Strozyk D, Rahman C, Lee LK, Fernandes EM, Claassen J, et al. Acute spinal cord ischemia: treatment with intravenous and intra-arterial thrombolysis, hyperbaric oxygen and hypothermia. Cerebrovasc Dis (2010) 29(1):95-8. doi:10.1159/000259618

13. Koch M, Sepp D, Prothmann S, Poppert H, Seifert CL. Systemic thrombolysis in anterior spinal artery syndrome: what has to be considered? J Thromb Thrombolysis (2016) 41(3):511-3. doi:10.1007/s11239-015-1281-8

14. Muller KI, Steffensen LH, Johnsen SH. Thrombolysis in anterior spinal artery syndrome. BMJ Case Rep (2012). doi:10.1136/bcr-2012-006862

15. Restrepo L, Guttin JF. Acute spinal cord ischemia during aortography treated with intravenous thrombolytic therapy. Tex Heart Inst J (2006) 33(1):74-7.

16. Jungehulsing GJ, Rossnagel $\mathrm{K}$, Nolte $\mathrm{CH}$, Muller-Nordhorn J, Roll S, Klein $\mathrm{M}$, et al. Emergency department delays in acute stroke - analysis of time between ED arrival and imaging. Eur J Neurol (2006) 13(3):225-32. doi:10.1111/j.1468-1331.2006.01170.x

17. Nolte CH, Malzahn U, Kuhnle Y, Ploner CJ, Muller-Nordhorn J, Mockel M. Improvement of door-to-imaging time in acute stroke patients by implementation of an all-points alarm. J Stroke Cerebrovasc Dis (2013) 22(2):149-53. doi:10.1016/j.jstrokecerebrovasdis.2011.07.004

18. Grassner L, Klausner F, Wagner M, McCoy M, Golaszewski S, Leis S, et al. Acute and chronic evolution of MRI findings in a case of posterior spinal cord ischemia. Spinal Cord (2014) 52(Suppl 1):S23-4. doi:10.1038/ sc. 2013.165

19. Sellner J, Luthi N, Schupbach WM, Gebhardt A, Findling O, Schroth G, et al. Diagnostic workup of patients with acute transverse myelitis: spectrum of clinical presentation, neuroimaging and laboratory findings. Spinal Cord (2009) 47(4):312-7. doi:10.1038/sc.2008.143

20. Freedman BA, Malone DG, Rasmussen PA, Cage JM, Benzel EC. Surfer's myelopathy: a rare form of spinal cord infarction in novice surfers: a systematic review. Neurosurgery (2016) 78(5):602-11. doi:10.1227/ NEU.0000000000001089

21. Cheng MY, Lyu RK, Chang YJ, Chen RS, Huang CC, Wu T, et al. Spinal cord infarction in Chinese patients. Clinical features, risk factors, imaging and prognosis. Cerebrovasc Dis (2008) 26(5):502-8. doi:10.1159/000155988

22. Masson C, Pruvo JP, Meder JF, Cordonnier C, Touze E, De La Sayette V, et al. Spinal cord infarction: clinical and magnetic resonance imaging findings and short term outcome. J Neurol Neurosurg Psychiatry (2004) 75(10):1431-5. doi:10.1136/jnnp.2003.031724
23. New PW, McFarlane CL. Retrospective case series of outcomes following spinal cord infarction. Eur JNeurol (2012) 19(9):1207-12. doi:10.1111/j.1468-1331.2012.03702.x

24. Romi F, Naess H. Spinal cord infarction in clinical neurology: a review of characteristics and long-term prognosis in comparison to cerebral infarction. Eur Neurol (2016) 76(3-4):95-8. doi:10.1159/000446700

25. Weidauer S, Nichtweiss M, Hattingen E, Berkefeld J. Spinal cord ischemia: aetiology, clinical syndromes and imaging features. Neuroradiology (2015) 57(3):241-57. doi:10.1007/s00234-014-1464-6

26. Pikija S, Trkulja V, Malojcic B, Mutzenbach JS, Sellner J. A high burden of ischemic stroke in regions of Eastern/Central Europe is largely due to modifiable risk factors. Curr Neurovasc Res (2015) 12(4):341-52. doi:10.2174/1567 202612666150731105554

27. Wolters FJ, Paul NL, Li L, Rothwell PM, Oxford Vascular S. Sustained impact of UK FAST-test public education on response to stroke: a population-based time-series study. Int J Stroke (2015) 10(7):1108-14. doi:10.1111/ijs.12484

28. Lecouturier J, Rodgers H, Murtagh MJ, White M, Ford GA, Thomson RG. Systematic review of mass media interventions designed to improve public recognition of stroke symptoms, emergency response and early treatment. BMC Public Health (2010) 10:784. doi:10.1186/1471-2458-10-784

29. Nardone R, Pikija S, Mutzenbach JS, Seidl M, Leis S, Trinka E, et al. Current and emerging treatment options for spinal cord ischemia. Drug Discov Today (2016) 21(10):1632-41. doi:10.1016/j.drudis.2016.06.015

30. Smith EE, Hassan KA, Fang J, Selchen D, Kapral MK, Saposnik G, et al. Do all ischemic stroke subtypes benefit from organized inpatient stroke care? Neurology (2010) 75(5):456-62. doi:10.1212/WNL.0b013e3181ebdd8d

31. Hawryluk G, Whetstone W, Saigal R, Ferguson A, Talbott J, Bresnahan $\mathrm{J}$, et al. Mean arterial blood pressure correlates with neurological recovery after human spinal cord injury: analysis of high frequency physiologic data. J Neurotrauma (2015) 32(24):1958-67. doi:10.1089/neu.2014.3778

32. Kwon BK, Curt A, Belanger LM, Bernardo A, Chan D, Markez JA, et al. Intrathecal pressure monitoring and cerebrospinal fluid drainage in acute spinal cord injury: a prospective randomized trial. J Neurosurg Spine (2009) 10(3):181-93. doi:10.3171/2008.10.SPINE08217

33. Warner FM, Cragg JJ, Jutzeler CR, Rohrich F, Weidner N, Saur M, et al. Early administration of gabapentinoids improves motor recovery after human spinal cord injury. Cell Rep (2017) 18(7):1614-8. doi:10.1016/j.celrep.2017.01.048

34. Adams HP Jr, del Zoppo G, Alberts MJ, Bhatt DL, Brass L, Furlan A, et al. Guidelines for the early management of adults with ischemic stroke: a guideline from the American Heart Association/American Stroke Association Stroke Council, Clinical Cardiology Council, Cardiovascular Radiology and Intervention Council, and the Atherosclerotic Peripheral Vascular Disease and Quality of Care Outcomes in Research Interdisciplinary Working Groups: the American Academy of Neurology affirms the value of this guideline as an educational tool for neurologists. Stroke (2007) 38(5):1655-711. doi:10.1161/ STROKEAHA.107.181486

35. Hacke W, Kaste M, Bluhmki E, Brozman M, Davalos A, Guidetti D, et al. Thrombolysis with alteplase 3 to 4.5 hours after acute ischemic stroke. $N$ Engl J Med (2008) 359(13):1317-29. doi:10.1056/NEJMoa0804656

36. Takeshita S, Ogata T, Mera H, Tsugawa J, Fukae J, Tsuboi Y. Time course of diffusion weighted image and apparent diffusion coefficient in acute spinal cord infarction: a case report and review of the literature. Rinsho Shinkeigaku (2016) 56(5):352-5. doi:10.5692/clinicalneurol.cn-000858

37. Kuker W, Weller M, Klose U, Krapf H, Dichgans J, Nagele T. Diffusionweighted MRI of spinal cord infarction - high resolution imaging and time course of diffusion abnormality. J Neurol (2004) 251(7):818-24. doi:10.1007/ s00415-004-0434-z

Conflict of Interest Statement: The authors declare that the research was conducted in the absence of any commercial or financial relationships that could be construed as a potential conflict of interest.

Copyright (C) 2017 Pikija, Mutzenbach, Kunz, Nardone, Leis, Deak, McCoy, Trinka and Sellner. This is an open-access article distributed under the terms of the Creative Commons Attribution License (CC BY). The use, distribution or reproduction in other forums is permitted, provided the original author(s) or licensor are credited and that the original publication in this journal is cited, in accordance with accepted academic practice. No use, distribution or reproduction is permitted which does not comply with these terms. 